\title{
Los primeros 18 meses del Acuerdo Multipartes Ecuador - Unión Europea
}

\section{The first 18 months of the Multiparty Agreement Ecuador - European Union}

INFORMACIÓN DEL

\section{ARTÍCULO}

Fecha de recepción: 8 de Febrero de 2019.

Fecha de aceptación: 9 de Mayo de 2019.

\footnotetext{
1 Magíster en Administración de Empresas, Escuela Politécnica del Ejército. Docente e investigador de la Universidad UTE-Ecuador.

E-mail: darwin.rosales@ute.edu.ec Código ORCID:

https://orcid.org/0000-0002-1788-782X

${ }^{2}$ Magíster en Negocios Internacionales y Gestión en Comercio Exterior, Universidad de Guayaquil. Docente e investigadora de la Universidad UTE-Ecuador.

E-mail: laura.delacruz@ute.edu.ec Código ORCID:

https://orcid.org/0000-0001-8278-3958
}

CITACIÓN: Rosales Nieto, D. E., \& De La Cruz Guerrero, L. A. (2019). Los primeros 18 meses del Acuerdo Multipartes Ecuador - Unión Europea. Podium, 35, 43-56.

doi:10.31095/podium.2019.35.3

ENLACE DOI:

http://dx.doi.org/10.31095/podium.201 9.35 .3
Darwin Eugenio Rosales Nieto ${ }^{1}$, Laura Angélica De La Cruz Guerrero ${ }^{2}$

\section{Resumen}

La firma del Acuerdo Multipartes entre Ecuador y la Unión Europea es el resultado de una historia de relaciones culturales, económicas y políticas que con el paso de los años se han ido fortaleciendo hasta convertir a Europa en el primer destino de las exportaciones no petroleras del Ecuador. Esta investigación tuvo por objetivo analizar el intercambio de mercancías no petroleras entre Ecuador y la Unión Europea en el período comprendido entre enero del año 2015 y junio del año 2018. Para ello se realizó un análisis comparativo de las estadísticas de organismos públicos y privados, obtenidas de sus bases de datos, de reportes y de boletines, lo que se complementó con una revisión bibliográfica que da soporte teórico a esta investigación. Los resultados permiten afirmar que la aplicación del Acuerdo Multipartes incide directamente en la cantidad de mercancías no petroleras comercializadas entre los actores.

\section{Palabras Clave:}

Acuerdo Multipartes; Ecuador; Unión Europea; Integración; Importaciones; Exportaciones.

Clasificación JEL: F15, M21.

\begin{abstract}
The signing of the multiparty agreement between Ecuador and the European Union is the result of a cultural, economic and political relationships history that has been strengthened over the years to the point where Europe has become the top destination for Ecuador's non-oil exports. The objective of this research was to analyze the exchange of non-oil goods between Ecuador and the European Union in the period between January 2015 and June 2018. For this purpose, a comparative analysis of the statistics of public and private organizations was made of their databases, reports and newsletters, which was complemented by a bibliographical review that gives theoretical support to this research. The results allow to affirm that the application of the Multiparty Agreement affects directly the amount of non-oil merchandise marketed among the actors.
\end{abstract}

Keywords:

Multiparty agreement; Ecuador; European Union; Integration; Import; Export.

JEL Classification: F15, M21.

\section{3}

PODIUM No. 35, Junio 2019, pp. 43-56

Universidad Espíritu Santo - UEES

ISSN: 1390-5473 e-ISSN: 2588-0969 


\section{Introducción}

Ecuador y la Unión Europea han impulsado procesos de integración desde hace varias décadas. Por un lado, Europa luego de la segunda guerra mundial toma consciencia de la importancia de emprender en procesos conjuntos que fortalezcan el intercambio comercial y financiero como opción para salir de la debacle en la que quedaron luego de prolongados períodos de conflicto. Aparece el concepto de integración económica que en líneas generales es un proceso a través del cual los países comprometidos buscan reducir $\mathrm{y}$, en última instancia, suprimir las barreras arancelarias y no arancelarias al libre tránsito de bienes, servicios y factores de la producción entre ellos (Hill, 2015). Surge entonces la Comunidad Europea del Carbón y del Acero (CECA), conformada por Alemania, Bélgica, Francia, Italia, Luxemburgo y Países Bajos, que constituye la génesis de lo que será el proceso de integración que mayor desarrollo ha alcanzado hasta hoy. En ese camino hubo tres momentos clave, el uno en 1951 cuando con el Tratado de París se creó la CECA, luego en 1957 con el atado de Roma se constituye la Comunidad Económica Europea o Mercado Común Europeo y el otro en 1993 que como resultado del Tratado de Maastricht se organiza la Unión Europea con doce países miembros (Ministerio de Asuntos Exteriores, Unión Europea y Cooperación, 2019). Las adhesiones continuaron hasta completar los 28 países que la conforman en la actualidad, al menos hasta que culmine la salida del Reino Unido.
En Latinoamérica, la idea integracionista empezó algo más tarde y ha tenido connotaciones diferentes. Es en Montevideo, en 1960, donde surge la Asociación Latinoamericana de Libre Comercio (ALALC). Sus once países miembros establecen como objetivo principal la creación de una zona de libre comercio. Luego de una evaluación de los avances logrados, en 1980, en Montevideo también, se modifica el tratado original y se constituye la Asociación Latinoamericana de Integración (ALADI), cuyos 13 países miembros se fijan como objetivo final el establecimiento de un Mercado Común Latinoamericano (ALADI, 2016).

La Comunidad Andina (CAN) se crea en 1996 con el Protocolo modificatorio de Trujillo con el objetivo de alcanzar metas conjuntas de desarrollo equilibrado y autónomo. Iniciaron la CAN Bolivia, Colombia, Ecuador, Perú y Venezuela, país este último que se retiró en 2006 (SICE, 1996).

En los años noventa del siglo pasado, los dos bloques iniciaron las conversaciones para alcanzar un acuerdo comercial; no obstante, diferencias en la política comercial de los gobiernos de los cuatro países andinos terminaron dividiendo una negociación que empezó en bloque y concluyó concretándose en fechas distintas para Colombia, Perú y Ecuador; Bolivia aun no ha decidido retomarla.

En el caso de Ecuador, después de un interrumpido proceso, en cuatro rondas de negociación se alcanza un acuerdo que 
entró en vigencia el 1 de enero de 2017 y que por su contenido implica un reto para los productores ecuatorianos que tienen una oportunidad para su crecimiento, ya que al frente tienen un mercado con alto poder adquisitivo que demanda de los productos que el país exporta. El reto está en industrializar la producción agrícola, pecuaria y pesquera y todas aquellas ramas de la producción en las que se envía materia prima, agregándoles valor no solamente como una forma de aprovechar los contenidos del acuerdo multipartes y las ventajas arancelarias que a este tipo de productos se les confiere, sino para aumentar las fuentes de empleo y mantener e incrementar el superávit en la balanza comercial. Estos cambios en la balanza comercial, que son el reflejo de la variación de los flujos de intercambio de las importaciones y exportaciones entre los actores del acuerdo, se constituyen en el propósito de esta investigación, a través de la cual se analizó el comportamiento de la comercialización de los principales productos no petroleros antes e inmediatamente después de su entrada en vigencia.

Conocer cómo reaccionan los mercados ante un escenario distinto en el que, por un lado se obtienen ventajas arancelarias, pero por otro se deben elevar los estándares de calidad de los productos para satisfacer la demanda de una población exigente, resulta particularmente importante; por ello, este estudio procura mostrar esas variaciones, de tal manera que permita contar con elementos objetivos que den claridad a los actores del comercio exterior.

\section{Revisión de literatura}

Partiendo de un concepto que permita contextualizar el tema de análisis, un Tratado de Libre Comercio (TLC) es un acuerdo entre dos o más países por medio del cual se busca facilitar el comercio de bienes y servicios, así como los flujos de inversión entre ellos (Romero-Pérez, 2006). La relación comercial entre la Unión Europea y Latinoamérica es parte de un proceso que tuvo un repunte en la década de los noventa del siglo anterior, cuando los acuerdos Norte-Sur, especialmente a partir de TLC liderados por Estados Unidos y la Unión Europea concentraron los mayores montos en comercio e inversión (Fairlie Reinoso, 2007). América Latina entendió este proceso e inició una intensa búsqueda de integración de la región promoviendo bloques desde la idea de los gobiernos o por iniciativa de los pueblos del continente (Arroyo, Rodríguez, y Castañed, 2009). El ALCA que luego daría lugar a la ALADI y la Comunidad Andina (CAN) comparten el objetivo de conformar un mercado común latinoamericano (Acuerdo de Cartagena, 1969), a estos procesos se suman MERCOSUR, ALBA, MCCA, entre los principales. Fue tal vez esta proliferación de acuerdos la que ha impedido una verdadera cohesión regional que finalmente, en un momento de coyuntura política, llevó a que en 2008 se concrete la Unión de Naciones Suramericanas UNASUR, en cuyo Tratado Constitutivo se afirma la determinación por construir una identidad y ciudadanía suramericanas $\mathrm{y}$ desarrollar un espacio regional integrado en lo político, económico, 
social, cultural, ambiental, energético y de infraestructura (Secretaría General UNASUR, 2011), no obstante, la liberalización comercial no se incluyó como parte del Tratado (Briceño-Ruiz y Ribeiro Hoffmann, 2015).

La CAN, por su parte, inició los acercamientos para lo que sería un TLC con la Unión Europea en medio de criterios a favor y en contra. Villagómez (2004), por ejemplo, considera que la globalización y los TLC profundizan las inequidades de género y las sociales, lo que hace necesario diseñar estrategias para enfrentarlos. Del otro lado están quienes como Sanahuja (2013) consideran que la suscripción de acuerdos de libre comercio con la Unión Europea, significa profundizar la integración económica garantizando la libre circulación de bienes y servicios y la aplicación de reglas comunes en distintos campos, aunque reconoce que un acuerdo de libre comercio es más fácil si se lo firma de manera bilateral, pues un acuerdo birregional exige condiciones mínimas de integración como la vigencia de una Unión Aduanera y un territorio aduanero común que en el caso de la CAN no existía plenamente, y en el caso de los países andinos es más difícil aún, ya que la savia que alimenta cualquier proceso de integración es la decisión política de los gobiernos (Andrade, 2013). Esta última consideración se confirma cuando, pese a haber iniciado los cuatro países miembros de la CAN las negociaciones como bloque, se hizo evidente que cada país asumía su propio nivel de interés en lograr que el Acuerdo de Asociación se concretara con la UE
(Alvear y Jaramillo, 2009) y Colombia y Perú mostraron mucho interés en firmar este Acuerdo que luego de complejas negociaciones inició su singladura en el año 2013 (Saura, 2013). No se pretende que los acuerdos comerciales sean la solución a los problemas de desarrollo, tampoco es justo ignorar el contexto social de estos, pues su aplicación necesariamente afectará en los flujos del comercio, dando como resultado ganadores y perdedores, estos últimos, lamentablemente, constituidos por los sectores vulnerables (Van den Putte, Orbie, Bossuyt, Martens, y De Ville, 2016).

Es posible distinguir dos grandes dificultades en las negociaciones entre la CAN y la Unión Europea. La primera es la ya citada falta de entendimiento político entre los países andinos y, la segunda, las asimetrías existentes con respecto a estos y los países de la Unión Europea. Esas dificultades para negociar en bloque han derivado en la concreción de acuerdos comerciales con terceras partes por Colombia y Perú, lo cual ha significado una disminución de las exportaciones intrarregionales de esos países (Brown y Torres, 2012).

Lo expuesto ha significado que, en el caso del Ecuador, las negociaciones se extiendan por 12 años, desde 2005 en que se iniciaron hasta la entrada en vigencia del acuerdo en enero de 2017. Una de las razones fue el pensamiento crítico en contra de los TLC de Rafael Correa, quien en 2007 asumió la presidencia del país (Acosta, Correa, Falconí, Jácome, y Ramírez, 2006); otra razón está en que la 
gestión del comercio exterior en el país se desarrolla en medio de una dicotomía entre lo técnico y lo político, dividiéndose las competencias entre el Ministerio de Industrias y la Cancillería, impidiendo una gestión óptima de la política comercial (Urigüen, 2015). La anterior devino en la retirada del proceso en 2009, sin embargo, cuando en 2012 la Unión Europea anunció el retiro del Sistema Generalizado de Preferencias a varios países, entre ellos al Ecuador, es cuando se decide retomar las negociaciones que se realizaron en cuatro rondas efectuadas en 2014 luego de las cuales se concretó el acuerdo (Latorre, 2017). Según Francisco Rivadeneira, ex Ministro de Comercio Exterior, el acuerdo firmado entre Ecuador y la Unión Europea, no obstante ser el mismo acuerdo negociado por Perú y Colombia, tiene especificidades que posibilitan se mantenga el modelo de desarrollo nacional (Aguas, 2016).

Las dificultades señaladas, no obstante no haber contribuido a una ágil negociación de un Acuerdo comercial entre las partes, tampoco ha interrumpido sus buenas relaciones, ante lo cual, la firma y entrada en vigencia del Acuerdo Multipartes entre la República de Ecuador y la Unión Europea consolida una importante historia de relacionamiento comercial, económico y político entre los países de la Comunidad Andina (CAN) y la Unión Europea (UE) y también de claros vínculos históricos $\mathrm{y}$ culturales, fruto de un devenir histórico común (Ministerio de Comercio Exterior, 2016).
La Unión Europea se ha convertido en el principal comprador de bienes y servicios a nivel mundial. En su conjunto, los países de la UE representan un mercado de alrededor de 514 millones de habitantes, de grandes oportunidades, con consumidores que valoran la calidad, la responsabilidad social y el trabajo de los pequeños productores; ámbitos en los que precisamente Ecuador ha puesto particular empeño en desarrollar y promover en sus negociaciones comerciales (Ministerio de Comercio Exterior, 2016). Este bloque de 28 países es la mayor economía mundial, el primer exportador e importador; en su territorio abarca al 7\% de la población del planeta y genera más de la cuarta parte de la riqueza mundial en términos de producto interno bruto (Comisión Europea, 2014). De allí la importancia de establecer un acuerdo comercial que dinamice el intercambio entre las dos partes reduciendo y eliminando las barreras comerciales impuestas a la compraventa de bienes y servicios, como resultado de lo cual se fomenta la creación de nuevas empresas que se tornan más competitivas, se incrementan las fuentes de empleo, fomenta la inversión entre los países intervinientes, y en definitiva refuerza la estabilidad macroeconómica y la estabilidad jurídica facilitando el comercio internacional (Cañada, 2015).

Ya que las exportaciones ecuatorianas se concentran en ocho países de la Unión Europea: Italia, España, Países Bajos, Alemania, Francia, Reino Unido, Bélgica y Grecia (Ministerio de Comercio Exterior, 2017), para el Ecuador es uno de los socios comerciales más 
importantes, de hecho, en los últimos años es el primer destino de sus exportaciones no petroleras (Ministerio de Comercio Exterior, 2014b) y con la vigencia del acuerdo las expectativas son altas, pues, según el Ministerio de Comercio Exterior (2014a), el Acuerdo Multipartes facilita la desgravación arancelaria del $99,7 \%$ de los productos agrícolas exportados tradicionalmente a Europa, de igual manera se desgrava el $100 \%$ de los productos relacionados con la industria ecuatoriana.

Los principales productos de exportación de Ecuador a la Unión Europea son: Banano, camarón, conservas de atún, cacao, flores, café y té, conservas de frutas y legumbres, otros productos de madera, jugos de frutas, confites y chocolates, demás frutas, aceites y extractos vegetales, pescado, brócoli y coliflor (Cámara de Comercio de Quito, 2018), debiéndose recalcar que la Unión Europea es el principal consumidor de las exportaciones ecuatorianas de actores de la economía popular y solidaria (EPS), representando un $47 \%$ del total de sus exportaciones al mundo (Ministerio de Comercio Exterior, 2016). La expectativa es que los productos de este sector experimenten un crecimiento a la entrada en vigor del Acuerdo.

En ese contexto, el acuerdo comercial Multipartes beneficia a Ecuador y a la Unión Europea, ya que permite a ambas partes comercializar de manera preferencial y recíproca bienes $\mathrm{y}$ servicios en un marco jurídico seguro, estable y transparente, brindando a las pequeñas y medianas empresas la opción de internacionalizarse y diversificar sus productos y abriendo la posibilidad de que la Unión Europea aporte inversiones, experiencia, conocimiento y tecnología (Delegación de la Unión Europea en Ecuador, 2014).

\section{Metodología}

Para el desarrollo de esta investigación se realizó una revisión bibliográfica de fuentes primarias $\mathrm{y}$ secundarias; para el análisis estadístico se consultaron las bases de datos de instituciones públicas como el Banco Central del Ecuador, Servicio Nacional de Aduana (SENAE), Ministerio de Comercio Exterior y Ministerio de la Producción, algunas cifras se las contrastó con la base de datos del Trade Map. Para las importaciones se realizó un análisis de la información que presenta el SENAE mensualmente, convirtiéndola en valores anuales. Se verificaron los datos por país de origen y por producto, considerando los valores FOB en cada subpartida analizada. Para las exportaciones el procedimiento fue similar considerando los países de destino. Se eligió el período comprendido entre enero del año 2015 a junio del año 2018 para tener un espacio de comparación de lo que fue el intercambio comercial entre el Ecuador y la Unión Europea dos años antes y dieciocho meses luego de la entrada en vigencia del Acuerdo Multipartes.

\section{Resultados}

Los resultados de la investigación se 
los ha sistematizado en tres grandes rubros que comprenden: primero, un análisis de la balanza comercial no petrolera; luego un estudio de los principales productos de exportación del Ecuador a la Unión Europea que incluye la variación de los montos comercializados y los principales destinos, y finalmente se analiza el comportamiento de las importaciones realizadas por el Ecuador desde su socio europeo.

\section{Balanza comercial}

Para el Ecuador, el mercado europeo es gravitante, pues la participación en la exportaciones no petroleras la confirma como su primer destino (Ministerio de Comercio Exterior, 2014b). La Tabla 1 muestra un ligero, pero sostenido incremento anual de las importaciones, mientras que en las exportaciones se evidencian los resultados de la vigencia del acuerdo, ya que de US \$ 2.874 millones en el año 2016, antes de su vigencia, pasó a US \$3.194 millones en el año 2017, el primer año de la aplicación del acuerdo. En el primer semestre del año 2018, las cifras se mantienen similares a los años anteriores, no obstante, de acuerdo a los registros históricos, en el segundo semestre se incrementarán y lo más probable es que superen a lo exportado en el año 2017.

Históricamente la balanza comercial no petrolera con la Unión Europea ha sido favorable al Ecuador, eso se confirma en la Tabla 1, según la cual, en los dos años previos al acuerdo hubo un incremento del saldo favorable, que pasó de US \$419 millones en el año 2015 a US \$1.227 millones en el año 2016. Para el año 2017, aunque las exportaciones crecieron con relación a los años anteriores, también lo hicieron las importaciones, lo que significó una balanza superavitaria para Ecuador, aunque menor al año 2016.

\section{Exportaciones}

La desgravación arancelaria del 99,7\% que el Acuerdo Multipartes contempló para los productos agrícolas ecuatorianos (Ministerio de Comercio Exterior, 2014a), permitió que el banano, el cacao y las flores estuviesen entre los cinco productos que encabezaban la lista de lo que Ecuador exporta mayoritariamente a Europa, que se complementa con el atún y camarones, productos de pesca que se desgravaron automáticamente a la entrada en vigencia del Acuerdo. En el período analizado, los cinco productos presentaron un crecimiento sostenido año tras año (ver

Tabla 1.

Importaciones y exportaciones no petroleras (millones de dólares).

\begin{tabular}{ccccccc}
\hline Año & $\begin{array}{c}\text { Importaciones } \\
\text { Totales }\end{array}$ & $\begin{array}{c}\text { Importaciones } \\
\text { UE }\end{array}$ & $\begin{array}{c}\% \\
\text { participación }\end{array}$ & $\begin{array}{c}\text { Exportaciones } \\
\text { FOB totales }\end{array}$ & $\begin{array}{c}\text { Exportaciones } \\
\text { FOB UE }\end{array}$ & $\begin{array}{c}\% \\
\text { participación }\end{array}$ \\
\hline 2015 & 16.747 & 2.157 & $12,88 \%$ & 10.655 & 2.576 & $24,18 \%$ \\
2016 & 13.083 & 1.647 & $12,59 \%$ & 11.493 & 2.874 & $25,01 \%$ \\
2017 & 15.822 & 2.068 & $13,07 \%$ & 12.315 & 3.194 & $25,94 \%$ \\
$2018^{*}$ & 8.734 & 1.148 & $13,14 \%$ & 7.105 & 1.758 & $24,74 \%$ \\
\hline
\end{tabular}

* A junio de 2018.

Fuente: Elaborado por los autores con información de SENAE (2018a, 2018b). 
Tabla 2

Exportaciones no petroleras hacia la UE (miles de dólares).

\begin{tabular}{clrrrr}
\hline \multicolumn{1}{c}{} & \multicolumn{1}{c}{2015} & 2016 & 2017 & \multicolumn{1}{c}{$2018^{*}$} \\
\hline Subpartida & $\begin{array}{c}\text { Descripción } \\
\text { arancelaria }\end{array}$ & $\begin{array}{c}\text { FOB } \\
\text { (Dólares) }\end{array}$ & $\begin{array}{c}\text { FOB } \\
\text { (Dólares) }\end{array}$ & $\begin{array}{c}\text { FOB } \\
\text { (Dólares) }\end{array}$ & \multicolumn{1}{c}{$\begin{array}{c}\text { FOB } \\
\text { (Dólares) }\end{array}$} \\
& Banano & $653.728,66$ & $903.983,11$ & $960.019,73$ & $561.010,66$ \\
1604 & Atún & $358.680,69$ & $472.758,28$ & $722.572,37$ & $366.250,79$ \\
0306 & Camarones & $495.284,18$ & $707.989,92$ & $710.047,05$ & $370.181,24$ \\
1801 & Cacao & $137.752,43$ & $171.659,90$ & $181.636,88$ & $58.903,17$ \\
0603 & Flores & $118.135,38$ & $177.221,84$ & $195.507,86$ & $178.353,00$ \\
2101 & Extractos, Esencias & $75.762,78$ & $61.817,46$ & $61.448,56$ & $23.577,88$ \\
& y Concentrados & & & & \\
2009 & Jugos de Frutas & $42.990,65$ & $38.913,47$ & $34.470,41$ & $15.363,82$ \\
1511 & Aceite de Palma & $4.890,18$ & $22.692,95$ & $38.003,33$ & $14.145,39$ \\
2008 & Frutas preparadas & $26.738,28$ & $30.531,14$ & $29.047,11$ & $16.569,67$ \\
4407 & Madera & $30.483,38$ & $32.613,74$ & $27.096,65$ & $11.595,81$ \\
\hline
\end{tabular}

* A junio de 2018 .

Fuente: Elaborado por los autores con información de SENAE (2018a).

Tabla 2). El caso del atún es especialmente destacable ya que hay un incremento del $53 \%$ entre el año 2016 y el año 2017. En cuanto a los otros cinco productos, sólo el aceite de palma muestra un crecimiento importante pues pasó de US\$22.692,95 miles en el año 2016 a US\$ 38.003,33 miles en el primer año del acuerdo, representando un incremento del $67 \%$. Se confirma que productos de la EPS como el banano, café, crustáceos, flores y pescados (Ministerio de Comercio Exterior, 2016), han experimentado un crecimiento importante. Los demás productos presentaron una reducción en su participación, lo cual aunque es en porcentajes menores, podría significar que el cambio de la matriz productiva no ha pasado del discurso, ya que estos productos corresponden a aquellos que han sido parte de algún proceso de industrialización.

Como se muestra en la Figura 1, los países en los que se concentra el mayor porcentaje de las exportaciones son pocos en

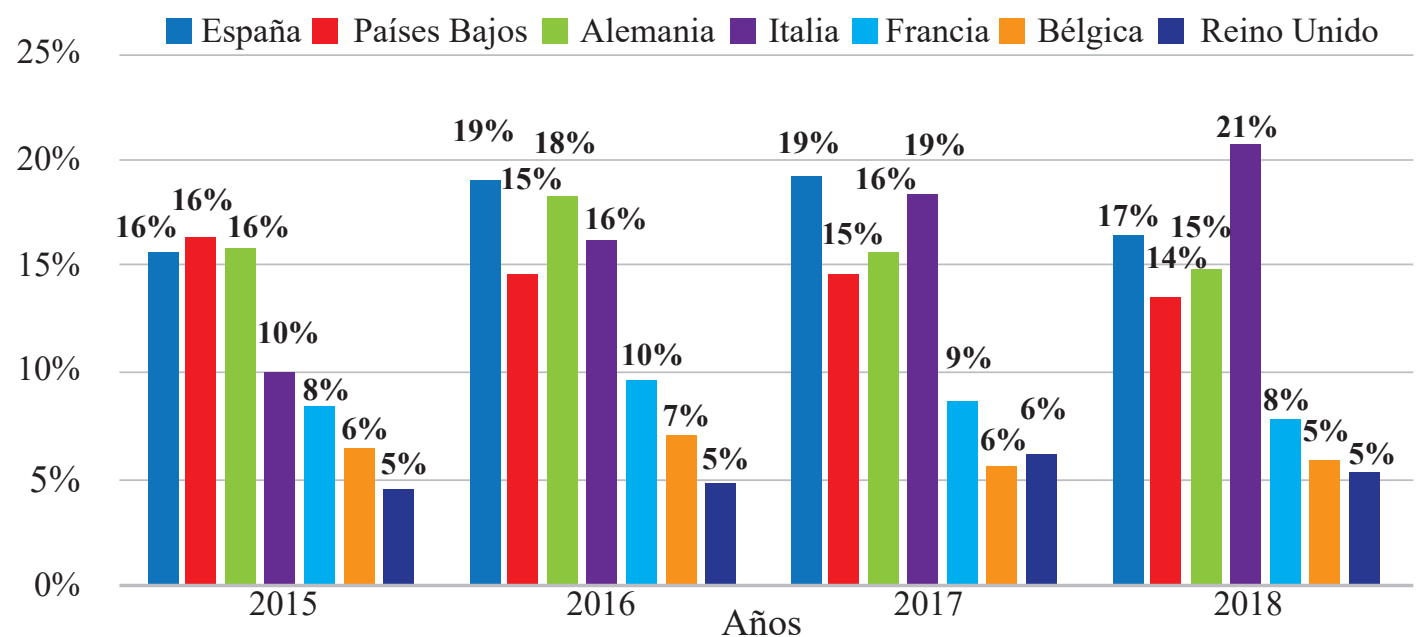

Figura 1. Principales destinos de las exportaciones ecuatorianas hacia la U.E. Fuente: Elaborado por los autores con información de SENAE (2018a). 
comparación con los 28 que conforman la Unión Europea, lo cual confirma la tendencia expresada por el Ministerio de Comercio Exterior (2017). Esto representa una gran oportunidad para los productos ecuatorianos, ya que existe demanda de lo que actualmente produce el país y la posibilidad de ampliar la oferta exportable está a la espera de decisiones tanto del sector público como de la empresa privada.

Los países europeos de destino de las exportaciones ecuatorianas se concentran en 7 de los 28 países que conforman la Unión, eso tiene varias explicaciones: la primera es que son países con infraestructura portuaria muy desarrollada y a los que históricamente arribaron los productos del Ecuador; también hay que considerar que la ruta de las naves que

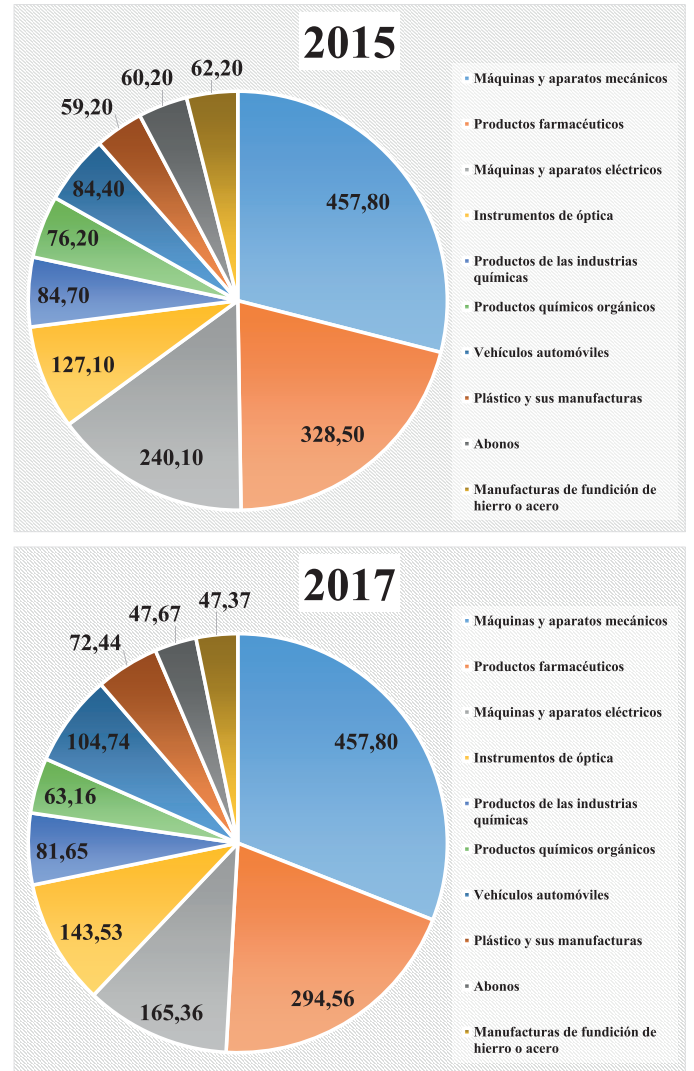

Figura 2. Importaciones no petroleras (millones de dólares). Fuente: Elaborado por los autores con información de SENAE (2018b). transportan la mercancía ecuatoriana, arriba a puertos que por su ubicación geográfica resultan más propicios, pues reducen tiempo y costo; la otra razón es que no necesariamente esos países son los que más consumen esos productos, sino que en aplicación del artículo 3 del GATT, una vez nacionalizados, pueden circular libremente por todos los países que son parte de este bloque comercial.

\section{Importaciones}

La Figura 2 muestra que los productos con altos componentes de industrialización son los que encabezan la lista de las importaciones que hace Ecuador desde la Unión Europea. De ellos, las máquinas, aparatos y artefactos mecánicos ocupan el primer lugar, no obstante que hay partidas

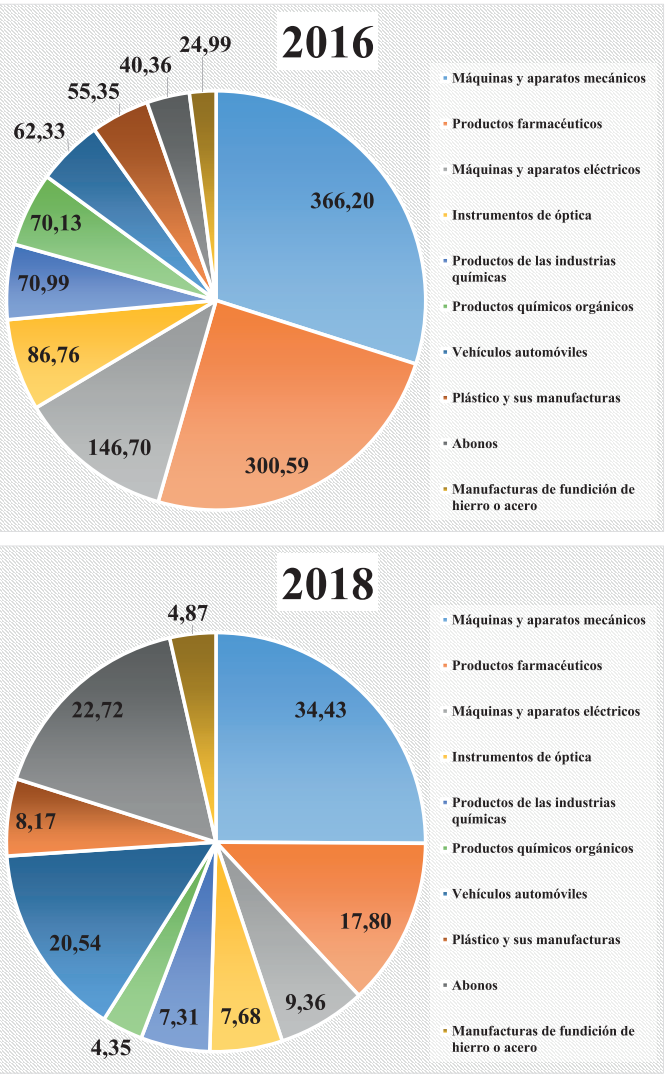


de este capítulo que no quedaron liberalizadas a partir de enero del año 2017 y su proceso de desgravación será gradual hasta en 10 años. Los productos farmacéuticos ocupan el segundo lugar entre los que más exporta Europa; un porcentaje de estos se liberó inmediatamente al inicio del acuerdo, aunque también tiene una lista que permanecerá en proceso de desgravación a 10 años; este grupo experimentó un decrecimiento en las importaciones que ha variado de US\$ 328 millones en el año 2015 a US\$ 300 millones en el año 2016, para el año 2017, ya con el acuerdo en vigor, cae a US \$294 millones. En este análisis uno de los productos que presenta un crecimiento interesante son los vehículos que de US\$ 62 millones importados en el año 2016 se incrementó a US\$ 105 millones en el año 2017, esto probablemente por la desgravación gradual que experimentan estas subpartidas, lo que influye favorablemente en el precio final del producto. En general, las importaciones del bloque europeo se incrementaron en un $26 \%$ entre el año 2016 y el año 2017, pasando de US\$ 1.646,5 millones a US\$ 2.067,6 millones.

La participación de los países europeos desde donde se importan las mercancías al Ecuador guarda relación con el tipo de productos que se comercializa, por ello es que Alemania lidera la lista con un $25 \%$ del total, porcentaje constante en los cuatro años analizados; en el año 2016, España e Italia exportaban porcentajes similares al Ecuador, en cantidades que giraban alrededor del $17 \%$, sin embargo, en el año 2017 ya con el acuerdo en aplicación, España incrementa al 24\% e Italia cae al $14 \%$. Los productos procedentes de Francia también redujeron su ingreso al Ecuador ya que del $10 \%$ en el año 2016 pasó al $7 \%$ en el año 2017, porcentaje que permanece similar en el primer semestre del año 2018. Bélgica, Reino Unido y los Países Bajos mantienen porcentajes cercanos al 5\% durante los cuatro años estudiados.

Es de resaltar que los siete países analizados en la Figura 3 representan el $85 \%$

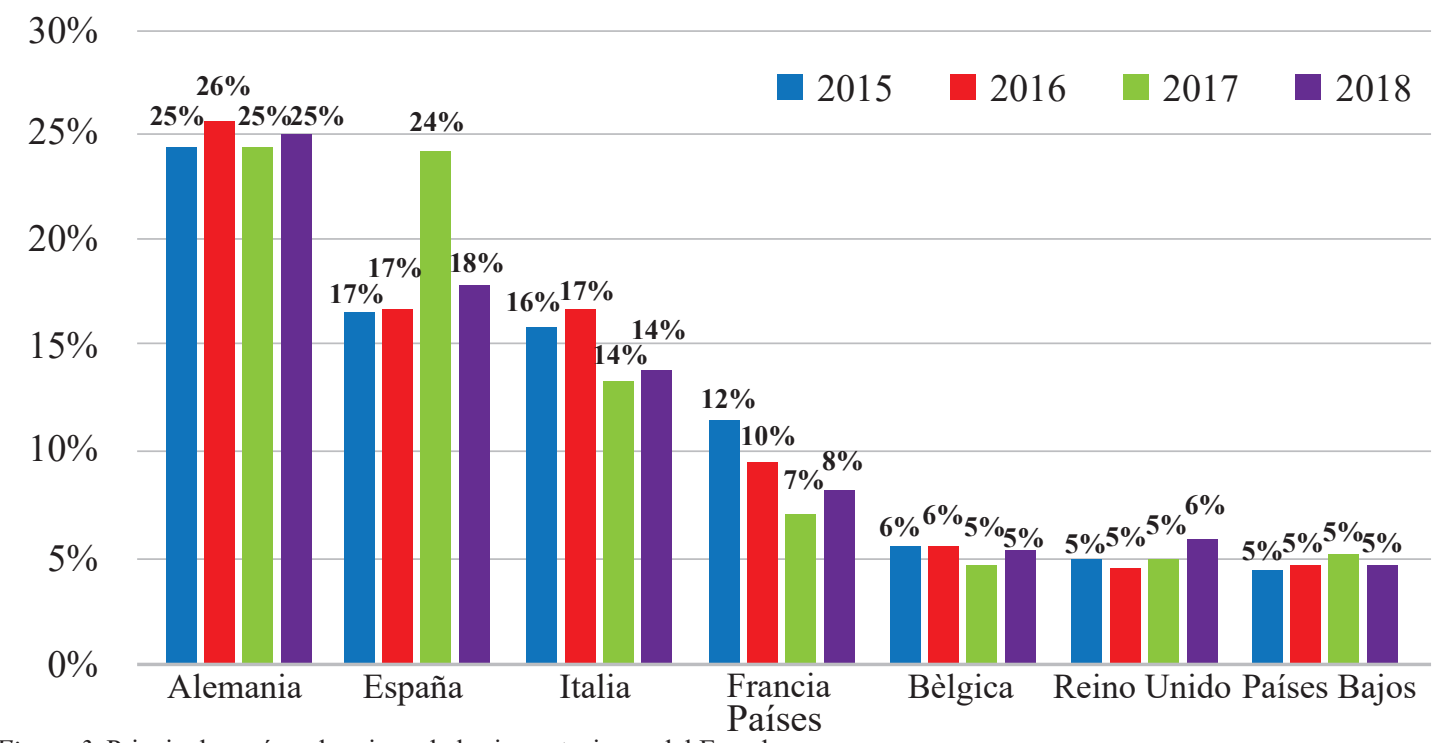

Figura 3. Principales países de origen de las importaciones del Ecuador . Fuente: Elaborado por los autores con información de SENAE (2018b). 
del total de lo que Ecuador compra a la Unión Europea, lo que significa una alta concentración en pocos oferentes y la posibilidad de explorar nuevas opciones en los demás países que también ofrecen los productos que Ecuador importa.

\section{Conclusiones}

En las últimas décadas, la Unión Europea ha sido uno de los mercados más importantes para el Ecuador, esta posición se consolida con la firma del Acuerdo Multipartes que entró en vigencia a partir del 1 de enero del año 2017. En una comparación entre el año 2016, es decir el inmediatamente previo, y el primer año de su ejecución, se aprecia que las exportaciones del Ecuador hacia el bloque europeo se incrementaron en $11 \%$, similar a lo sucedido entre el año 2015 y el año 2016. En lo que respecta a las importaciones, la investigación permite confirmar el impacto que la aplicación de medidas paraarancelarias tiene en el comercio, solamente basta comparar lo que Ecuador importó de Europa en el año 2015 y el año 2016 para verificar que hubo un decrecimiento del $23,6 \%$, pues en este último año es cuando se sintieron los efectos de la aplicación de esta sobretasa sobre los productos importados. El efecto de la aplicación del acuerdo, en cuanto a las exportaciones de la Unión Europea al Ecuador, se verifica desde el primer año en que significó un incremento del $25,6 \%$, ello se debe a la supresión de salvaguardias por parte de Ecuador, a la eliminación inmediata de aranceles en un buen número de productos, a la reducción gradual en otros y a la simplificación de trámites para el comercio, lo cual en definitiva significa la posibilidad del consumidor ecuatoriano de acceder a productos de calidad a menores precios.

Lo expresado anteriormente se confirma al analizar la balanza comercial no petrolera, la cual ha sido históricamente superavitaria para Ecuador, y en el primer año de vigencia del acuerdo Multipartes se mantiene así, aunque en porcentaje menor, es decir que, mientras en el año 2016 el saldo a favor para el Ecuador fue de 1226, 9 millones de dólares, en el año 2017 fue de 1126,7 millones de dólares, lo que equivale a un $8 \%$ menos en el superávit.

Al analizar el tipo de productos que el Ecuador exporta a la Unión Europea, se comprueba que encabezan la lista los productos primarios como banano, flores, cacao y camarón y algunos que han sido sometidos a procesos de industrialización como el pescado; esto demuestra la debilidad de la industria nacional para agregar valor a sus productos, que siendo de gran calidad, pierden opciones de posicionarse mejor en Europa ofreciendo productos transformados que no solamente son más demandados sino que significaría mayores ingresos por exportaciones, generación de fuentes de empleo y apertura de nuevos mercados. Es de destacar que el $90 \%$ de las exportaciones del Ecuador se concentran en siete países de la Unión Europea, lo cual representa una oportunidad para, incrementando la producción $y$ diversificando la oferta exportable, acceder a 20 países con los cuales el comercio es incipiente o nulo. 
En cuanto a las importaciones, los productos altamente industrializados son los más comprados por Ecuador. La eliminación de sobretasas arancelarias, la supresión de aranceles a partir de enero del año 2017 y la reducción gradual en algunos productos, ha incidido para que el ingreso de productos desde Europa se incremente notablemente, disminuyendo el saldo a favor que ha mantenido Ecuador en la balanza comercial; este es un aspecto que se lo deberá monitorear para evitar que los saldos favorables se reduzcan en los próximos años, para lo cual un buen manejo del sector exportador contribuirá efectivamente. En cuanto a los países europeos de origen de las exportaciones hacia el Ecuador, el 80 $\%$ de lo que importa proviene de siete países, lo que podría significar que se están ignorando a países que pueden constituirse en potenciales proveedores y que con un buen manejo de las negociaciones internacionales podría hacérselo en mejores condiciones.

Esta investigación se limita a analizar los primeros 18 meses de vigencia del Acuerdo Multipartes, por lo que, como trabajo futuro, se propone realizar un seguimiento anual de su evolución e impacto en sectores específicos.

\section{Referencias}

Acosta, A., Correa, R., Falconí, F., Jácome, H., y Ramírez, R. (2006). El rostro oculto del TLC. Quito: ABYA-YALA.

Acuerdo de Integración Subregional Andino-Acuerdo de Cartagena. (1969). Recuperado de: https://idatd.cepal.org/Normativas/CAN/ Espanol/Acuerdo_de_Cartagena.pdf
Aguas, L. (2016). La Economía Popular y Solidaria como proyecto político postneoliberal de Ecuador. Caso: Acuerdo Comercial Unión Europea-Ecuador. Revista PUCE, (100), 313-342.

Andrade, A. (2013). César Montaño: La CAN es el único proceso de integración completo e integral en América Latina. Recuperado de: https://www.uasb.edu.ec/web/spondylus/ contenido?cesar-montano-la-can-es-el-un ico-proceso-de-integracion-completo-e-i ntegral-en-america-latina

Asociación Latinoamericana de Integración- ALADI. (2016). Quienes somos. Recuperado de http://www.aladi.org/sitioaladi/quienesSo mos.html

Alvear, A. y Jaramillo, G. (2009). Negociaciones CAN-UE: la integración se cayó del barco. Revista La tendencia, (9), 28-31.

Arroyo, A., Rodríguez, G. y Castañed. N. (2009). The European Union: promoter of regional integration in Latin America? Rhetoric and Reality. Recuperado de: https://www.tni.org/files/download/eula-i ntegration_0.pdf

Briceño-Ruiz, J. y Ribeiro Hoffmann, A. (2015). Post-hegemonic regionalism, UNASUR, and the reconfiguration of regional cooperation in South America. Canadian Journal of Latin American and Caribbean Studies, 40(1), 48-62. DOI: $10.1080 / 08263663.2015 .1031475$

Brown, A. y Torres, P. (2012). La relación comercial Comunidad Andina- Unión Europea y la postura de Ecuador. Latinoamérica, 55(2), 75-99.

Cámara de Comercio de Quito. (2018). Boletín de Comercio Exterior 2018. Recuperado de: https://ccq.ec/boletin-comercio-exterior/

Cañada, A. (2015). La importancia de los tratados de Libre Comercio. Recuperado de: https://www.camaranavarra.com/camara/ 
blog/1767/la-importancia-de-los-tratados -de-libre-comercio

Comisión Europea. (2014). Política regional - Hacer que las regiones y ciudades europeas sean más competitivas, fomentar el crecimiento y crear empleo. Recuperado de: https://ec.europa.eu/regional_policy/inde $\mathrm{x} . \mathrm{cfm}$ ?action=publications.details\&langu ageCode $=$ es\&publication $I d=672$

Delegación de la Unión Europea en Ecuador. (2014). Acuerdo Comercial Ecuador - Unión Europea. Recuperado de:

https://eeas.europa.eu/sites/eeas/files/carti lla_acuerdo_comercial_ue-ecuador_0.pdf

Fairlie Reinoso, A. (2007). Acuerdos regionales en Sudamérica: entre la integración y la fragmentación (una perspectiva andina). Comentario Internacional. Revista Del Centro Andino De Estudios Internacionales, (8), 95-104.

Hill, C. (2015). Negocios Internacionales: Cómo competir en el mercado global (10a ed.). México D.F.: McGraw Hill.

Latorre, J. (2017). El desarrollo de las negociaciones en el Acuerdo Comercial Multipartes de la UE con Ecuador. Recuperado de: https://repositorio.flacsoandes.edu.ec/han dle/10469/13557

Ministerio de Asuntos Exteriores, Unión Europea y Cooperación. (2019). El Proceso de Construcción Europea. Recuperado de: http://www.exteriores.gob.es/Portal/es/Poli ticaExteriorCooperacion/UnionEuropea/P aginas/ProcesosConstruccionEuropea.aspx

Ministerio de Comercio Exterior. (2014a). El Acuerdo Comercial Ecuador - Unión Europea. Recuperado de:

https://www.comercioexterior.gob.ec/wpcontent/uploads/downloads/2015/04/CA RTILLA-UNION-EUROPEA-1.pdf

Ministerio de Comercio Exterior. (2014b). El Acuerdo Comercial Ecuador-Unión Europea.
Recuperado de:

https://www.comercioexterior.gob.ec/acu erdo-comercial-ecuador-union-europea/

Ministerio de Comercio Exterior. (2016). Memorias de las negociaciones del Acuerdo Multipartes entre Ecuador y la Unión Europea. Quito, Ecuador: Ministerio de Comercio Exterior.

Ministerio de Comercio Exterior. (2017). Exportaciones hacia la UE se incrementaron en un 14\% los 7 primeros meses de 2017. Recuperado de:

https://www.comercioexterior.gob.ec/exp ortaciones-hacia-la-ue-se-incrementaronen-un-14-los-7-primeros-meses-de-2017/

Romero-Pérez, J. E. (2006). Tratado de Libre Comercio Estados Unidos - Centroamérica República Dominicana. Análisis desde la perspectiva ideológica y del Derecho Económico (2da. ed.). San José: Instituto de Investigaciones Jurídicas Universidad de Costa Rica.

Sanahuja, J. (2013). La Unión Europea y el Regionalismo Latinoamericano: Un balance. Investigación \& Desarrollo, 21(1), 156-184.

Saura, J. (2013). Implicaciones de derechos humanos en el tratado de libre comercio entre Colombia y la Unión Europea. InDret Revista para el Análisis del Derecho, 4, 1-25.

Secretaría General UNASUR (2011). Tratado Constitutivo de la Unión de Naciones Suramericanas. Recuperado de: https://www.unasursg.org/images/descar gas/DOCUMENTOS\%20CONSTITUTI VOS\%20DE\%20UNASUR/Tratado-UN ASUR-solo.pdf

Servicio Nacional de Aduana del Ecuador - SENAE. (2018a). Exportaciones. Recuperado de: https://www.aduana.gob.ec/exportaciones

Servicio Nacional de Aduana del Ecuador - SENAE. (2018b). Importaciones. Recuperado de: 
https://www.aduana.gob.ec/importaciones

SICE. (1996). Protocolo modificatorio del Acuerdo de Integración Subregional Andino (Acuerdo de Cartagena). Recuperado de: http://www.sice.oas.org/trade/junac/carta _ag/trujillo.asp

Urigüen Eljuri, Maria Carolina. Institucionalidad Estatal para el manejo del comercio exterior en el caso del Ecuador en el periodo 2007 - 2013. Quito, 2015, 93 p. Tesis (Maestría en Relaciones Internacionales. Mención en Economía y Finanzas). Universidad Andina Simón Bolívar, Sede Ecuador. Área de Estudios Sociales y Globales.

Van den Putte, L., Orbie, J., Bossuyt, F., Martens D. y De Ville, F. (2016). ¿Cuál es el rostro social de los nuevos acuerdos comerciales de la UE? Más allá del enfoque "suave". Revista Latinoamericana de Políticas y Acción Pública. 3(1), 101-111.

Villagómez, M. (2004). Acuerdo comercial Multipartes Ecuador - Unión Europea. Revista AFESE, 56, 11-51. 